\title{
Microstructures and Mechanical Properties of Rolled 6013 Type Aluminum Alloy*
}

\author{
Fubao Zhang \\ Engineering Institute of \\ Advanced \\ Manufacturing and \\ Modern Equipment \\ Technology, Jiangsu \\ University, Zhenjiang \\ 212013, China \\ School of Mechanical \\ Engineering, Nantong \\ University, Nantong \\ 226019, China
}

\author{
Xiaojing $\mathrm{Xu}$ \\ Engineering Institute of \\ Advanced \\ Manufacturing and \\ Modern Equipment \\ Technology, Jiangsu \\ University, Zhenjiang \\ 212013, China
}

\author{
Zhigang Liu \\ Engineering Institute of \\ Advanced \\ Manufacturing and \\ Modern Equipment \\ Technology, Jiangsu \\ University, Zhenjiang \\ 212013, China
}

\author{
Zhilan Ju \\ School of Mechanical \\ Engineering, Nantong \\ University, Nantong \\ 226019, China
}

\author{
Yuyang Jin \\ School of Mechanical \\ Engineering, Nantong \\ University, Nantong \\ 226019, China
}

\begin{abstract}
Microstructures and properties of rolled 6013 type aluminum alloy were investigated by optical microscopy (OM), scanning electron microscopy (SEM), transmission electron microscopy (TEM), X-ray diffraction and hardness testing, tensile testing at ambient temperature, the strengthening and toughening mechanism of high strength and good plasticity were analyzed. The results indicate that grains are elongated along the rolling direction rendered as fibrous, square subgrain is formed due to the dislocation delivery inside the grain; After peak aging, a large amount of acicular phase is found on the alloy matrix, which is the main strengthening phase of precipitation strengthening; The tensile strength, yield strength and elongation of rolled 6013 type aluminum alloy are $482.21 \mathrm{MPa}, 419.42 \mathrm{MPa}$ and $10.0 \%$ after peak aging treatment, respectively; High strength is due to the high density dislocation by rolling, and the aging phase preferentially precipitates at the subgrain boundary, and increase the nucleation rate of the second phase. The improvement of the plasticity of rolled 6013 type aluminum alloy is mainly related to the grain refinement of the alloy and the second phase dispersed distribution.
\end{abstract}

Keywords-6013; rolling; strengthening and toughening mechanism; dislocation strengthening

\section{INTRODUCTION}

With the rapid development of aerospace, military and transportation equipment, the demand for high-performance metal materials is growing. The preparation of materials with high strength and good plasticity has been a hot topic in the field of materials science and technology research [1]. Ultrafine (including submicron and nanometer scale) grain materials attract much attention due to their excellent physical, mechanical and forming properties, which are different from traditional materials. Severe plastic deformation (SPD), such as equal channel angular pressing (ECAP), high pressure torsion (HPT), accumulate roll bonding (ARB), etc. is an effective method to prepare ultrafine grain materials, it can refine the internal structure of polycrystalline materials to submicron or even nanometer scale. However, these methods are limited in the industrial application because of the complexity of preparation process, restrictions of preparation material size, inhomogeneous microstructures, etc. [2]. Furthermore, the influence of work hardening, grain boundary condition and grain orientation result in the high strength and low plasticity of the alloy [3]. Rolling is a major technology of plastic deformation in industry, it can carry out large strain deformation to the alloy, and continuous production of the sheet metal. Rolling and corresponding heat treatment can effectively regulate the grain boundary condition and grain distribution so as to improve the strength and plasticity $[4,5]$.

6013 aluminum alloy is finding increasing usage due to the low cost and beneficial properties such as medium strength, good weldability, corrosion resistance and immunity to stresscorrosion cracking [6-8]. Compared with 2024-T3 aluminum alloy, the strength of 6013-T6 increases by $12 \%$, but the corrosion resistance is similar, and it has higher anti-fatigue performance and damage-tolerance. 6013-T6 aluminum alloy can replace 2024-T3, T4 on the application of Navy's P-7A aircraft, airbus A380 and so on [9, 10]. The latest study found that the performance of 6013 aluminum alloy can be further improved by optimizing the alloy composition, large strain processing and subsequent heat treatments [11-13].

The microstructure and mechanical properties of 6013 type aluminum alloy were studied by means of optical microscopy, scanning electron microscopy, transmission electron microscopy and X-ray diffraction, to analyze the mechanism of high strength and good plasticity of the alloy. Meanwhile, it provides the initial technical foundation and theoretical basis for improving the performance of 6013 type aluminum alloy.

\section{EXPERIMENTAL PROCEDURES}

The staring materials used in the present work are commercial purity aluminum, commercial purity magnesium; $\mathrm{Al}-10 \% \mathrm{Si}, \mathrm{Al}-10 \% \mathrm{Mn}, \mathrm{Al}-50 \% \mathrm{Cu}, \mathrm{Al}-4 \% \mathrm{Zr}, \mathrm{Al}-10 \% \mathrm{Sr}$, the studied alloy was prepared in an intermediate frequency crucible furnace. The temperature of alloy melt was maintained at $800^{\circ} \mathrm{C}$ and then was cast into a cylindrical iron moulds. The chemical composition of 6013 type aluminum alloy is $\mathrm{Al}$ $1.36 \mathrm{Mg}-1.02 \mathrm{Si}-0.92 \mathrm{Cu}-0.55 \mathrm{Mn}-0.08 \mathrm{Zn}-0.13 \mathrm{Fe}-0.12 \mathrm{Zr}-0.03 \mathrm{Sr}$ (mass friction, \%) measured by SPECTRO spectrometer. The as-cast 6013 type alloy ingots was homogenized at $470^{\circ} \mathrm{C}$ for 
$24 \mathrm{~h}$, and then deformed by $150 \%$, among the deformation, the alloys were annealed at $430^{\circ} \mathrm{C}$ for $0.5 \mathrm{~h}$. The bars were solutionized at $560^{\circ} \mathrm{C}$ for $2 \mathrm{~h}$, quenched in the water, and immediately placed on a rolling mill for simultaneous rolling. The line speed was $2.2 \mathrm{~m} / \mathrm{min}$ and the total deformation is $70.8 \%$. The aging treatment was carried out in DHG-9030 electric drying oven.

The microstructures of the 6013 type aluminum alloy were investigated by OLYMPUS BX51M optical microscopy performed via grinding, polishing which subsequently underwent etching by Keller reagent $(1 \% \mathrm{HF}+1.5 \% \mathrm{HCl}+$ $2.5 \% \mathrm{HNO}_{3}+95 \% \mathrm{H}_{2} \mathrm{O}$ ). The morphology and distribution of the precipitates were carried out on a JEM-2100 (HR) transmission electron microscopy (TEM). The samples were prepared by the standard double-jet electronpolishing method. The microhardness of the alloy was measured on a TMVS-1 microindentation tester under a load of $200 \mathrm{~g}$ for $15 \mathrm{~s}$. Each hardness was averaged over 5 measurements. The tensile samples were cut along the rolling direction of the sheets and tested on a WDW-200G machine. The tensile fracture surfaces were studied by a JEOL JSM-IT300 scanning electronic microscopy. The structural characterization was performed by quantitative XRD. Quantitative XRD measurements were performed with a D/max-2500PC diffractometer using $\mathrm{Cu} \mathrm{K} \alpha$ radiation.
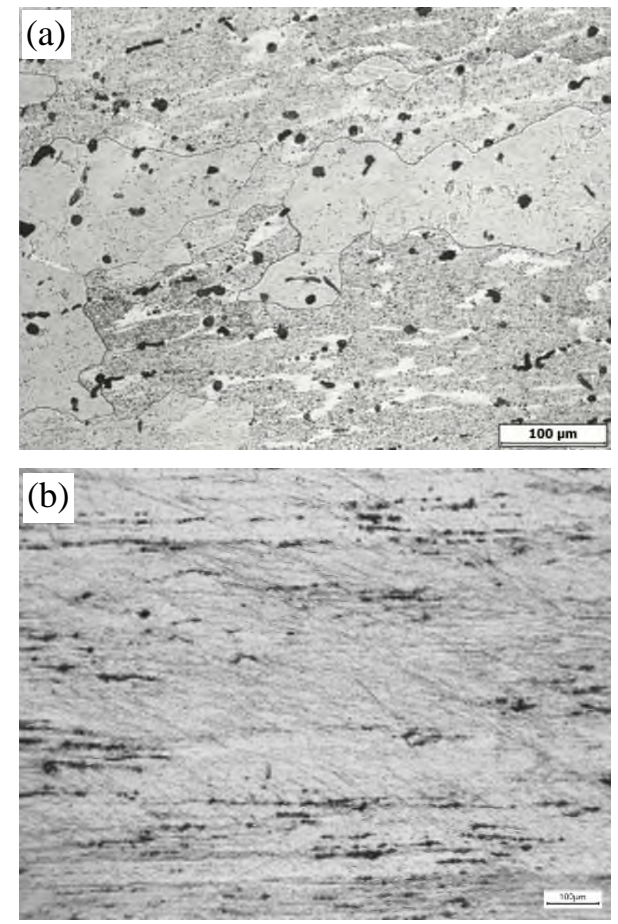

Fig. 1. OM of 6013 type aluminum alloy (a) dissolved at $560^{\circ} \mathrm{C}$ for $2 \mathrm{~h}$; (b) rolled.

\section{RESULTS}

\section{A. Microstructure}

Microstructures of 6013 type aluminum alloy are shown in Fig. 1. The grain of the dissolved alloy has recrystallized and the grain size is large; some black undissolved phases are distributed on the surface, which are $\mathrm{Mg}_{2} \mathrm{Si}$ phases analyzed by EDS, as shown in Fig. 1 (a). Microstructures of rolled alloy are shown in Fig. 1 (b). It suggests that the grain of rolled alloy is stretched to form the fibrous structure and the black undissolved phases are distributed along the deformed belt.

TEM images of rolled 6013 type aluminum alloy is shown in Fig. 2. Subgrain was formed, the dislocations are accumulated on the subgrain boundary, as shown in Fig. 3, a large number of needle shape $\beta^{\prime \prime}$ phase were precipitated after the peak aging treatment, which is the main precipitation phase to strengthen aluminum alloy matrix.

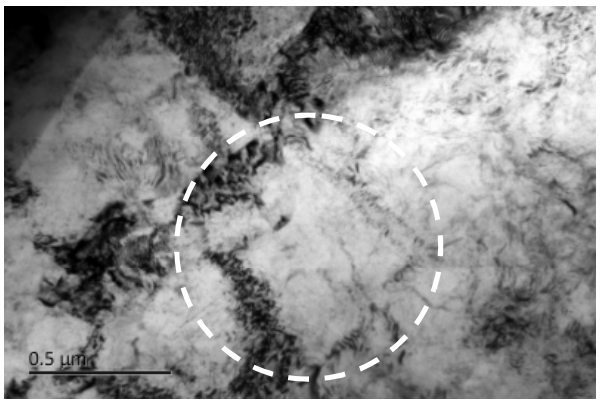

Fig. 2. TEM images of rolled 6013 type aluminum alloy.

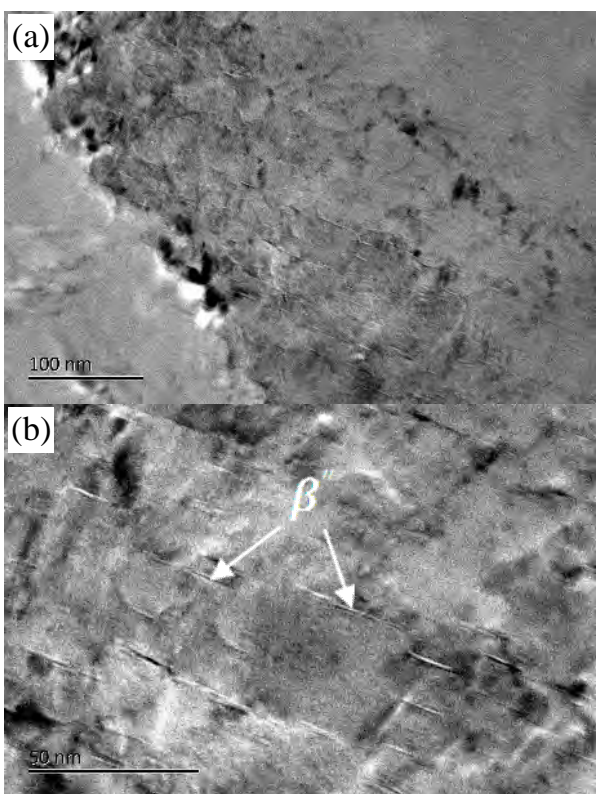

Fig. 3. TEM images of rolled 6013 type aluminum alloy after T6 treatment. (a) the precipitation of grain boundary; (b) the precipitated phase of $\beta^{\prime \prime}$

\section{B. Mechanical properties}

1) Hardness. The Vikers hardness vs aging time at different aging temperatures of rolled 6013 type aluminum alloys is shown in Fig. 4. From the trend of hardness, the aging hardening time of the alloy is shortened with the increasement of temperature. When the aging temperature is in the range of $100^{\circ} \mathrm{C}$ to $171^{\circ} \mathrm{C}$, the hardness of the alloy increases with the aging temperature. When the temperature exceeds $171^{\circ} \mathrm{C}$, the hardness of the alloy began to fall. When the rolled alloy was aging at $171^{\circ} \mathrm{C}$ for $1.5 \mathrm{~h}$, the hardness reached the highest, the value is $155.76 \mathrm{HV}$. Taking into 
account the economic factors in industrial application, and the large scale aluminum alloy which needs a certain period of time to be fully heated, the best peak aging process of rolled 6013 type aluminum alloy is $151{ }^{\circ} \mathrm{C} \sim 171{ }^{\circ} \mathrm{C}$ for $1.5 \sim 3 \mathrm{~h}$.

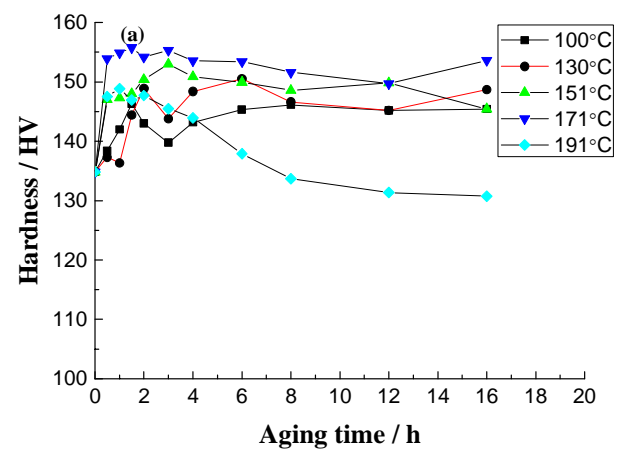

Fig. 4. Vikers hardness vs aging time at different aging temperatures of rolled 6013 type aluminum alloys

2) Tensile properties and fracture morphology. The rolled 6013 type aluminum alloy was prepared for peak-aging (T6) by $171^{\circ} \mathrm{C} \times 3 \mathrm{~h}$, and the dissolved alloy was also carded out, the peak-aging treatment was $191^{\circ} \mathrm{C} \times 4 \mathrm{~h}[13,14]$. Tensile properties of 6013 type aluminum alloy after peak-aging treatment is shown in table 1. Compared to dissolved alloy, the tensile strength of rolled 6013 type aluminum alloy increases by $110.24 \mathrm{MPa}$ and the yield strength improves by 89.08 MPa, and the elongation is equivalent.

TABLE I. TENSILE PROPERTIES OF 6013 TYPE ALUMINUM ALLOY AFTER PEAKAGING TREATMENT

\begin{tabular}{llll}
\hline & $\begin{array}{l}\text { Tensile strength / } \\
\mathrm{MPa}\end{array}$ & $\begin{array}{l}\text { Yield strength } \\
\text { / MPa }\end{array}$ & $\begin{array}{l}\text { Elongation } \\
/ \%\end{array}$ \\
\hline Dissolved & 371.97 & 330.34 & 11.3 \\
Rolled & 482.21 & 419.42 & 10.0 \\
\hline
\end{tabular}

Fig. 5 show fracture morphology of tensile specimen of 6013 type aluminum alloys after T6 treatment. The fracture surface of dissolved 6013 type aluminum alloy contains dimple and grain boundary cracks (as shown in Fig. 5a), which indicate that the fracture is the mixed fracture caused by the intergranular fracture and grain boundary fracture. The fracture surface dimples of rolled 6013 type aluminum alloy are small and uniform, which belongs to the dimple fracture, showing a good plasticity.

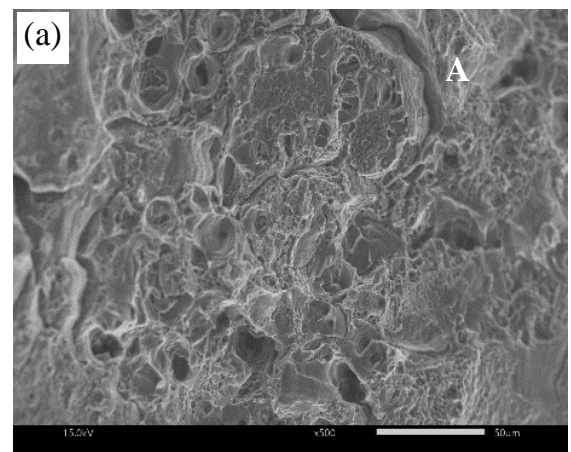

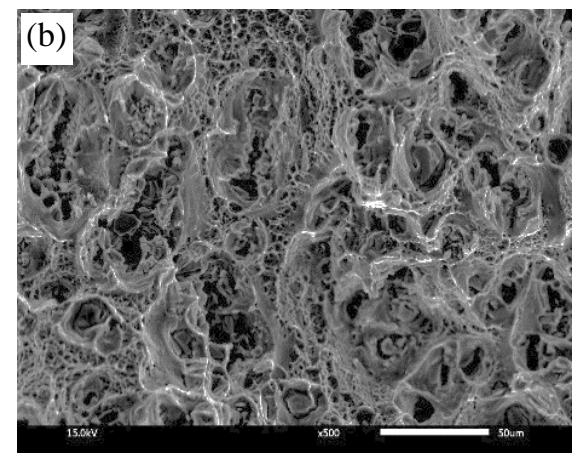

Fig. 5. Fracture morphology of tensile specimen of 6013 type aluminum alloys after T6 treatment (a) dissolved; (b) rolled

\section{DISCUSSION}

A. Strengthening mechanism of rolled 6013 type aluminum alloy

XRD patterns of dissolved and rolled 6013 type aluminum alloys are shown in Fig. 6.
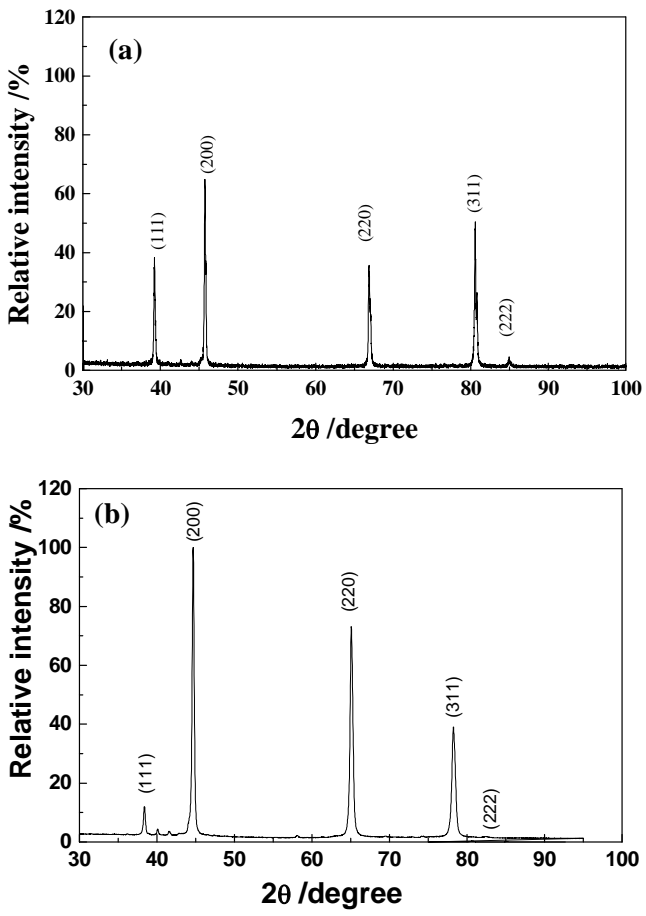

Fig. 6. XRD diffraction spectrum of 6013 type aluminum alloys after T6 treatment (a) dissolved; (b) rolled.

The relationship between average grain size of coherent diffraction region $(d)$, average lattice strain $\left(\left\langle e^{2}\right\rangle^{1 / 2}\right)$ and halfheight width $(\delta 2 \theta)$, the highest value of the diffraction peak $\left(\theta_{0}\right)$ and the $\mathrm{Cu}-\mathrm{K} \alpha$ ray wavelength $(\lambda)$ can be expressed by the Hall function as follows:

$$
\frac{(\delta 2 \theta)^{2}}{\tan ^{2} \theta_{0}}=\frac{\lambda}{d}\left(\frac{\delta 2 \theta}{\tan \theta_{0} \sin \theta_{0}}\right)+25\left\langle e^{2}\right\rangle
$$


Fig. 7 shows the XRD half-height width of dissolved and rolled 6013 type aluminum alloy after T6 aging, and the relationship between $(\delta 2 \theta)^{2} / \tan ^{2} \theta_{0}$ and $\delta 2 \theta /\left(\tan \theta_{0} \sin \theta_{0}\right)$ fitted by the least squares method. The grain size $(d)$ and lattice strain $\left(\left\langle e^{2}\right\rangle^{1 / 2}\right)$ can be calculated by the formula (1).The relationship between the dislocation density $(\rho)$, grain size $(d)$ and the lattice strain $\left(\left\langle e^{2}\right\rangle^{1 / 2}\right)$ can be described by the following function:
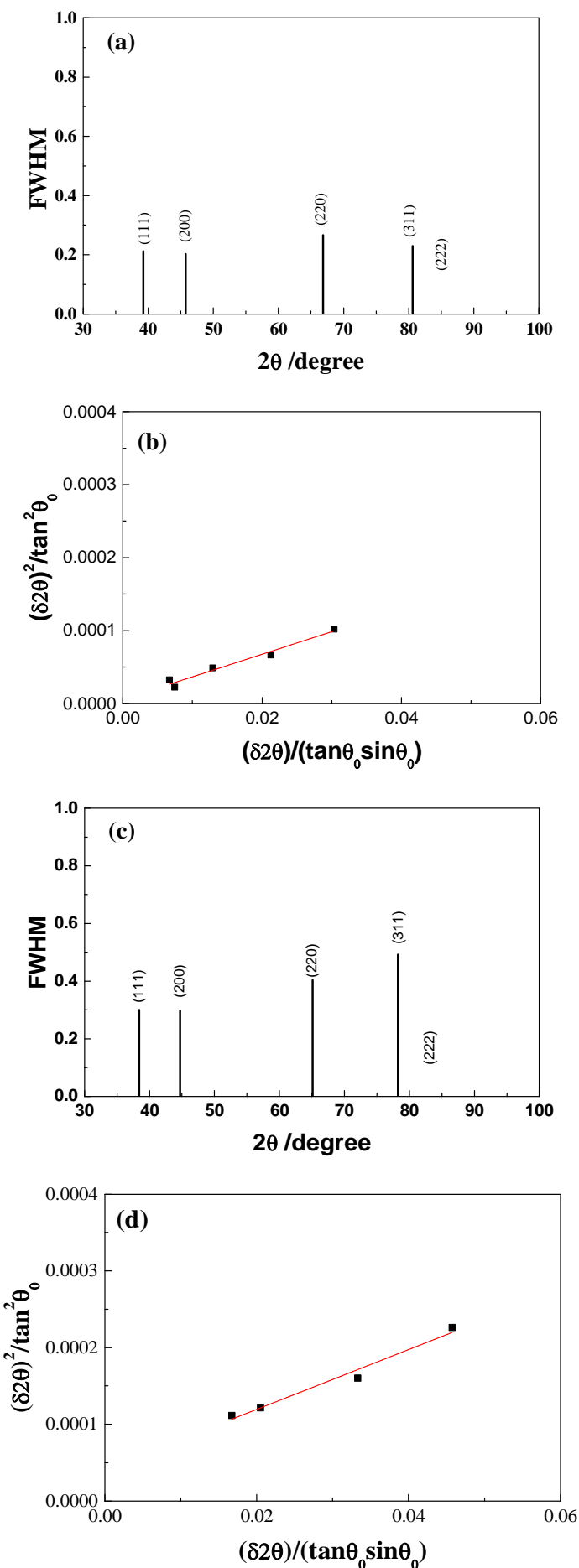

Fig. 7. FWHM and Integral breadth analysis of 6013 type aluminum alloy after T6 treatment (a) (b) dissolved; (c) (d) rolled

$$
\rho=2 \sqrt{3}\left(e^{2}\right\rangle^{1 / 2} /(d \times b)
$$

Where Burgers Vector $b$, for $\mathrm{Al}$, is $0.286 \mathrm{~nm}$. The dislocation density of the 6013 type aluminum alloy can be calculated by the above equation. The relationship between the contribution of the dislocation to the yield strength $\left(\sigma_{\rho},\right)$ and the dislocation density $(\rho)$ is generally described as a function relation:

$$
\sigma_{\rho}=\mathrm{M} \alpha \mathrm{Gb} \rho^{1 / 2}
$$

Where $M$ is Taylor to factor, taking $3.06, \alpha$ is the numerical factor, taking $0.24, G$ is shear modulus, taking $26 \mathrm{GPa}$ and $b$ is Burgers Vector, taking $0.286 \mathrm{~nm}$, the contribution of dislocation to the yield strength $\left(\sigma_{\rho}\right)$ can be calculated by means of formula (3).

The average grain size of coherent diffraction region $(d)$, average lattice strain $\left(\left\langle e^{2}\right\rangle^{1 / 2}\right)$, dislocation density $(\rho)$ and contribution of the average grain size, lattice strain, dislocation density and contribution of dislocation to the yield strength $\left(\sigma_{p},\right)$ calculated by XRD analysis are shown in Table 2 .

TABLE II. SOME MICROSTRUCTURAL AND MECHANICAL FEATURES CALCULATED FROM XRD DATA

\begin{tabular}{lll}
\hline & Dissolved & Rolled \\
\hline$d / \mathrm{nm}$ & 49.858 & 39.502 \\
$\left(e^{2}\right)^{1 / 2} / \%$ & 0.0005 & 0.0012 \\
$\rho / 10^{14} \mathrm{~m}^{-2}$ & 1.157 & 3.955 \\
$\sigma_{\rho} / \mathrm{MPa}$ & 58.75 & 108.60 \\
\hline
\end{tabular}

The yield strength of aluminum alloy under solid solution plastic deformation - aging is mainly composed of lattice friction stress $\sigma_{0}$, dislocation strengthening $\sigma_{\rho}$, low angle grain boundary strengthening $\sigma_{L A G B}$, high angle grain boundary strengthening $\sigma_{\text {HAGB }}$, solid solution - aging precipitation strengthening $\sigma_{s s-p p t}[15]$. Due to the complex interaction between dislocations and low angle grain boundary intensities, these two enhancement terms can be superposed twice, and then linearly superimposed on other enhancement terms. The formula is as follows:

$$
\sigma=\sigma_{0}+\left(\sigma_{\rho}^{2}+\sigma_{L A G B}^{2}\right)^{1 / 2}+\sigma_{L A G B}+\sigma_{s S-p p t}
$$

For aluminum alloy, the lattice friction stress is generally $20 \mathrm{MPa}$. The yield strength of rolled 6013 type aluminum alloy is $89.08 \mathrm{MPa}$ higher than that of dissolved alloy, and the contribution of dislocation to yield strength increasement is $49.85 \mathrm{MPa}$. Other factors such as grain refinement, solid solution-aging precipitation strengthening value is $39.23 \mathrm{MPa}$. The strength of rolled 6013 type aluminum alloy is the result of the combination of grain refinement, solid solution-aging precipitation strengthening and dislocation strengthening, the high density dislocation introduced by rolling deformation is the main reason for the improvement of strength. 


\section{B. Effect of rolling on plasticity of 6013 type aluminum alloy}

6013 type aluminum alloy is a type of precipitation strengthening aluminum alloy, whose strength and plasticity were affected by number, size and distribution of the second phase's precipitation. Large strain rolling deformation will accumulate a large number of dislocations in the aluminum alloy matrix, dislocation of the settlement, slip, aggregation and polygonalization formatting subgrain. The subgrain boundary is a high energy region with dislocated aggregates, which forms the deformation energy storage. The deformation energy storage increases the precipitation power of the precipitation phase, so that the precipitation phase is preferentially precipitated at subgrain boundary, which is favorable to the nucleation rate increasement. At the same time, the structure defect of dislocations formed by plastic deformation provide more locations to the heterogeneous nucleation of the precipitated phase, which speed up the diffusion of atoms and promote precipitation phase nucleation. In the aging process of 6013 type aluminum alloy, the dislocation of high density formed by the high nucleation rate and rolling deformation make the precipitation phase more and smaller, it changes the number and distribution characteristics of the precipitated phase after aging. When the sample is stretched, subgrains and the second phase precipitated within the subgrains hinder the slip of dislocation, then the dislocation plug was formed at the weak interface between the precipitation phase and the matrix. When the stress concentration of the dislocations is larger than that of the weak interface, micropores are formed at the weak interface and expand along the weak interface to form small dimples containing the precipitated phases. Therefore, the large strain rolling deformation not only refines the alloy grain, improves the strength of the alloy, but also to maintain a good plasticity.

\section{CONCLUSIONS}

(1) The grains are elongated as fibrous structure along the rolling direction, square shape subgrain is formed due to the dislocation delivery inside the grain; After peak ageing, a large amount of needle shape $\beta^{\prime \prime}$ phase is found on the alloy matrix, which is the main strengthening phases for precipitation strengthening.

(2) The tensile strength, yield strength and elongation of rolled 6013 type alloy are $482.21 \mathrm{MPa}, 419.42 \mathrm{MPa}$ and $10.0 \%$ after peak aging treatment, respectively; High strength is due to the high density dislocation formed by rolling.

(3) High strength of 6013 type aluminum alloy is obtained after rolling, the high density dislocation caused by rolling deformation is the main reason for the improvement of the strength.

(4) High density dislocation formed by rolling results in the preferential precipitation of aging phase along the subgrain boundary, increasement of the second phase nucleation rate, the improvement of the distribution of precipitation phase and the fine grains, which is the main reason of improved plasticity of rolled 6013 type aluminum alloy.

\section{ACKNOWLEDGMENT}

The author would like to acknowledge financial support provided by Colleges and Universities in Jiangsu Province Plans to Graduate Research and Innovation Projects (CXLX12_0620), Key Research Projects of Jiangsu Province (BE2016116), University Natural Science Foundation of Jiangsu Province (16KJD460006) and Project of Nantong Science and Technological Plans (GY12016056).

\section{REFERENCES}

[1] X.M. Zhang, Y.L. Deng, Y. Zhang. "Development of High Strength Aluminum Alloys and Processing Techniques for The Materials". Acta Metallurg. Sin. vol. 03, pp. 257-271, 2015.

[2] C.P. Wang, F.G. Li, B. Chen, et al. "Severe Plastic Deformation Techniques for Bulk Ultrafine-grained Materials". Rare. Metal. Mater. Eng. vol. 06, pp. 941-946, 2012.

[3] Z.X. Kang, Y.H. Peng, X.M. Lai, et al. "Research status and application prospect of ultrafine grained and/or nano-crystalline metallic materials processed by severe plastic deformation". Chinese J. Nonfer. Metal. vol. 04, pp. 587-598, 2010.

[4] X.J. Xu, L. Jiang, W.J. Lu, et al. "Effect of Rolling and Subsequent Heat Treatme nt on Tensile Property and Crystal Orientation of $5052 \mathrm{Al}$ Alloy”. Rare. Metal. Mater. Eng. vol. 01, pp. 245-248, 2014.

[5] Z. Wang, H. Li, F. Miao, et al. "Improving the strength and ductility of $\mathrm{Al}-\mathrm{Mg}-\mathrm{Si}-\mathrm{Cu}$ alloys by a novel thermo-mechanical treatment". Mater. Sci. Eng.: A, vol. 607, pp. 313-317, 2014.

[6] S.S. Park, H. Garmestani, G.T. Bae, et al. "Constitutive analysis on the superplastic deformation of warm-rolled $6013 \mathrm{Al}$ alloy”. Mater. Sci. Eng. A, vol. 435, pp. 687-692, 2006.

[7] R. Braun. "Investigations on the long-term stability of 6013-T6 sheet". Mater. Charact. vol. 56, pp. 85-95, 2006.

[8] A.C. Oliveira, R.H.M. Siqueira, R. Riva, et al. "One-sided laser beam welding of autogenous T-joints for 6013-T4 aluminium alloy”. Mater. Des. vol. 65, pp. 726-736, 2015.

[9] R.S. Kaneko, L. Bakow, E.W. Lee. "Aluminum alloy 6013 sheet for new US navy aircraft”. Int. J. Fatif. vol. 42, no. 5, pp. 16-18, 1990.

[10] C.X. Cao. "One Generation of Material Technology, One Generation of Large Aircraft". Acta Aeronaut. Et Astronaut. Sin. vol. 03, pp. 701-706, 2008 .

[11] S.J. Ai. "A Study on The Heat Treatment Process and Microstructure of A New 6013 Aluminum Alloy”. Zhenjiang: Jiangsu University, 2013

[12] F.B. Zhang, X.J. Xu, Y.K. Zhang, et al. "Microstructure and Properties of 6013 Type Aluminum Alloy Produced by Cyclic Channel Die Compression Process". Rare. Metal. Mater. Eng. vol. 43, no. 11, pp. 2819-2823, 2014.

[13] F.B. Zhang. "Primary Study on Micro-alloying and Properties of 6013 Type Aluminum Alloy". Zhenjiang: Jiangsu University, 2011.

[14] S.J. Ai, K.M. Chen, X.J. Xu, et al. "Effect of Aging on Properties of ZrSr Microalloyed 6013 Aluminum Alloy". Heat Treat. Metal. vol. 06, pp. 71-75, 2013.

[15] M. Cabibbo. "Microstructure strengthening mechanisms in different equal channel angular pressed aluminum alloys". Mater. Sci. Eng.: A, vol. 560, pp. 413-432, 2013. 